\title{
Eficácia na utilização de córneas no transplante penetrante
}

\author{
Efficacy in cornea utilization for penetrating keratoplasty
}

Vinícius Coral Ghanem ${ }^{1}$

David Leonardo Cruvinel Isaac ${ }^{1}$

Maurício Abujamra Nascimento ${ }^{1}$

Rosane Silvestre de Castro ${ }^{2}$

Newton Kara-José ${ }^{3}$

\section{R E S U M O}

Objetivos: 1) Verificar qual o impacto da criação do Cadastro Técnico Único (CTU) para o Hospital das Clínicas da Universidade de Campinas (Unicamp) no tempo de preservação de córneas utilizadas em transplantes penetrantes eletivos, e 2) comparar a incidência de falência primária em transplantes penetrantes de córnea nos períodos pré e pós-criação do CTU. Métodos: Foi realizado estudo retrospectivo no Hospital de Clínicas da Unicamp, avaliando-se 15 transplantes penetrantes de córnea consecutivos entre 1 de janeiro e 30 de abril de 2000 e 24 transplantes consecutivos entre 1 de maio e 20 de setembro de 2000 (córneas sob o controle do Cadastro Técnico Único), num total de 39 transplantes. Resultados: O tempo médio entre a preparação das córneas e o transplante foi de 3,8 dias $( \pm 1,78)$ no período pré-CTU, e de 6,0 dias $( \pm 2,97)$ no período pós-CTU, representando aumento no tempo de preservação de $36,7 \%$. Houve diferença estatisticamente significativa ( $\mathrm{p}=0,02)$ entre os dois grupos. Nenhum caso de falência primária do enxerto foi observado entre os 39 pacientes transplantados nos dois grupos. Conclusão: Com base nestes resultados, conclui-se que a nova disposição do Sistema Estadual de Transplantes aumentou de forma estatisticamente significativa o período de permanência das córneas no meio de preservação, o que pode comprometer o tempo de vida útil do transplante, aumentar a incidência de falência primária ou levar a maior número de córneas perdidas por excederem o tempo de preservação limite, preconizado na literatura.

Descritores:Presenvaçãodetecido;Transplantedecómea;Bancosdetecidos/organização \&administração;Sistemasdeinformaçãohospitalar;Doadoresdetecidos

I N T R O D U Ç ̃̃ O

Em 1 de maio de 2000 entrou em vigor a resolução SS12, de janeiro de 2000, da Secretaria de Saúde do Estado de São Paulo, que regulamenta a estrutura organizacional e operacional do Módulo de Transplante de Córnea.

As atividades relativas aos transplantes de córneas passaram a ser coordenadas pelo Sistema Estadual de Transplantes e desenvolvidas pelas Centrais de Notificação, Captação e Distribuição de Órgãos/Tecidos (CNCDO) e Organizações de Procura de Córneas (OPC's).

Estas mudanças tiveram por objetivo centralizar a captação e homogeneizar a distribuição de córneas entre suas sub-regionais e facilitar o controle do Sistema Nacional de Transplante sobre as atividades desenvolvidas ${ }^{(1)}$.

O tempo prolongado de preservação ou a conservação inadequada das córneas constituem fatores de risco importantes para falência primária ${ }^{(2)}$. Mesmo após a criação de meios que possibilitam a preservação das córneas por até 14 dias, estudos experimentais e clínicos mostraram maior perda endotelial e falência primária com os meios de conservação quando se excede período de 7 dias $^{(3-4)}$. 
Este estudo teve por objetivos: verificar qual o impacto da criação do Cadastro Técnico Único (CTU) para o Hospital das Clínicas da Unicamp no tempo de preservação de córneas utilizadas em transplantes penetrantes eletivos, e comparar a incidência de falência primária em transplantes penetrantes de córnea nestes dois períodos.

\section{MÉ T OD OS}

Foi realizado, no Hospital das Clínicas da Unicamp, estudo retrospectivo onde se avaliou 15 transplantes penetrantes de córnea consecutivos entre 1 de janeiro e 30 de abril de 2000 e 24 transplantes consecutivos entre 1 de maio e 20 de setembro de 2000, córneas sob o controle do CTU, num total de 39 transplantes.

Os transplantes de córnea foram realizados por residentes do terceiro ano, orientados por médicos assistentes, utilizando-se a mesma técnica cirúrgica. Os olhos doadores foram enucleados até 6 horas após o óbito e mantidos em câmara úmida contendo cloranfenicol, sob refrigeração de $4^{\circ} \mathrm{C}$, até por 12 horas, quando então as córneas foram preparadas e colocadas no meio de preservação, que permitiam um tempo de armazenamento de até 14 dias.

Para a utilização das córneas doadoras considerou-se a idade do doador (até 70 anos), o tempo entre a morte e a enucleação (até 6 horas) e o tempo entre a enucleação e a preparação da córnea (até 12 horas).

As cirurgias foram realizadas sob anestesia geral, utilizandose trépanos de diâmetro entre 7,25 e $8,5 \mathrm{~mm}$. A diferença na trepanação do botão doador/receptor foi de $0,25 \mathrm{~mm}$. A técnica cirúrgica utilizada foi a ceratoplastia penetrante com 16 pontos interrompidos de fio de monofilamento de nylon 10-0. O anel de sustentação de Flieringa foi utilizado em casos de pacientes obesos e quando o transplante penetrante de córnea foi associado à extração extracapsular da catarata. Ao final das cirurgias foi realizada injeção subconjuntival de $0,5 \mathrm{ml}$ de fosfato dissódico de dexametasona a $4 \mathrm{mg} / \mathrm{ml}$ (Ariston) e $0,5 \mathrm{ml}$ de gentamicina $40 \mathrm{mg} / \mathrm{ml}$ (Gentaron ${ }^{\circledR}$ - Ariston). Nas primeiras 24 horas os pacientes permaneceram internados, em repouso relativo e com curativo oclusivo.

Os pacientes tiveram alta hospitalar após avaliação oftalmológica com ênfase na ausência de saída de humor aquoso pela incisão, sutura posicionada, câmara anterior formada e ausência de sinais infecciosos.

Como medicação pós-operatória foi utilizado colírio de acetato de prednisolona a $1 \%$ (Predfort $^{\circledR}$ - Allergan) de $2 / 2$ horas e tobramicina a $0,3 \%$ de $4 / 4$ horas. Os pacientes foram avaliados no 1ํ, 7ํ, 15ำ e 30ํ dias pós-operatórios, ou em intervalos menores quando necessário.

Considerou-se falência primária do botão doador a persistência de edema corneano do 10 ao 30 을 dia pós-operatório, na ausência de outros fatores de risco, como aumento da pressão intra-ocular, hipotonia, inflamação ocular e trauma.

O teste utilizado para análise estatística foi o Mann-Whitney com nível de significância de $p<0,05$. No cálculo estatístico foi incluído o tempo decorrido entre a preparação da córnea doadora e o transplante, além da incidência de falência primária nos transplantes eletivos. Os transplantes terapêuticos de urgência foram excluídos.

\section{RESULTADOS}

Antes da entrada em vigor do CTU, a idade dos receptores variou de 19 a 87 anos, sendo a média de 37,97 anos $( \pm 21,90)$.

Com relação às indicações dos transplantes, ceratocone foi responsável por 9 casos $(60 \%)$, edema corneano da pseudofacia 4 casos $(26,67 \%)$ e outras opacidades corneanas 2 casos (13,33\%) (Gráfico 1).

O tempo médio entre a preparação das córneas e o transplante foi de 3,8 dias $( \pm 1,7)$, com mediana de 3 , variando de 1 a 6 dias (Quadro 1).

Após a entrada em vigor do CTU, a idade dos receptores variou de 10 a 74 anos, sendo a média de 39,13 anos $( \pm 22,26)$.

Com relação às indicações dos transplantes: ceratocone foi responsável por 14 casos $(58,33 \%)$, edema corneano da pseudofacia 5 casos $(20,83 \%)$ e outras opacidades corneanas 5 casos $(20,83 \%)$ (Gráfico 1$)$.

O tempo médio entre a preparação das córneas e o transplante foi de 6,0 dias $( \pm 2,97)$, com mediana de 6 , variando de 2 a 11 dias (Quadro 1).

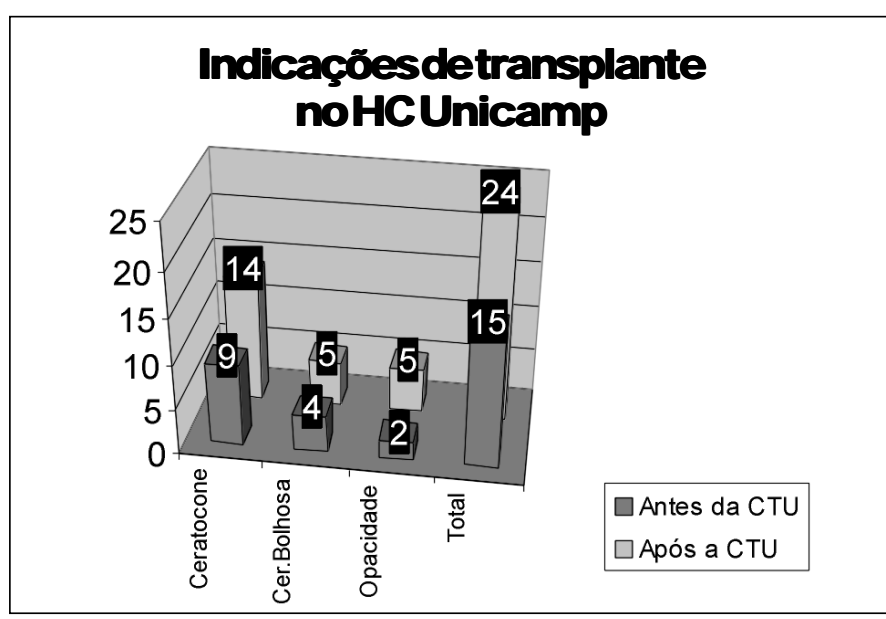

Gráfico 1. Indicações de transplantes de córnea no Hospital das Clínicas da Unicampnos períodos prée pós a criação do cadastro técnicounico

\begin{tabular}{|c|c|c|c|}
\hline & $\begin{array}{l}\text { Tempode } \\
\text { permanência }\end{array}$ & Desviopadrão & Medlana \\
\hline PeríodopréCTU & 3,8 & 1,78 & 3 \\
\hline Período pós CTU & 6,0 & 2,97 & 6 \\
\hline \multicolumn{4}{|c|}{ CTU=cadastrotécnicoúnico } \\
\hline
\end{tabular}


Houve diferença estatisticamente significativa $(\mathrm{p}=0,02)$ entre os dois grupos, quando considerado o tempo entre a preparação das córneas doadoras e o transplante, o que representa um aumento de $36,7 \%$ no tempo de preservação.

Não foi observado caso de falência primária do enxerto entre os 39 pacientes transplantados nos dois grupos.

D I S C U S S ÃO

Um dos objetivos do CTU é proporcionar maior controle sobre a captação, bem como organizar a distribuição de córneas no Estado de São Paulo ${ }^{(1)}$. Esta centralização poderia levar à demora entre a captação/preparação e a distribuição das córneas, diminuindo o tempo disponível entre a convocação do paciente e realização do transplante. Esse atraso poderia causar perda de córneas ou levar a realização de transplantes utilizando córneas que permaneceram no meio de preservação por um período próximo ao limite máximo recomendado, o que consistiria em fator de risco para a falência primária do enxerto ${ }^{(3-5)}$.

Além de se observar diferença estatisticamente significativa $(\mathrm{p}=0,02)$ entre o tempo de preparação e a realização do transplante nos dois grupos (média de 3,8 dias no período pré CTU e de 6,0 dias pós CTU), 7 córneas $(29,17 \%)$ utilizadas no período pós CTU, permaneceram no meio de preservação por mais de 7 dias. No período pré CTU, nenhuma córnea utilizada foi armazenada por mais de 6 dias.

Molina e Souza ${ }^{(5)}$, ao estudar a preservação de córneas no meio McCarey-Kaufman (M-K), observaram que o aspecto funcional do endotélio já estava comprometido após 72 horas de preservação. Atribuíram esse fenômeno a dois fatores: diminuição da adesão das células endoteliais à membrana de Descemet e perda de células endoteliais, que se intensifica com o aumento no tempo de estocagem. Com base nesses resultados, recomendou-se que o tempo de preservação no meio M-K fosse reduzido, a no máximo, 48 horas. Wong et al. ${ }^{(3)}$ e Bourne ${ }^{(4)}$ observaram que córneas preservadas por mais de 7 dias em meios contendo sulfato de condroitina, apresentaram maior perda endotelial e falência primária. Portanto um tempo prolongado de preservação causa maior perda endotelial, o que pode diminuir o tempo de vida útil do transplante.

Mesmo não sendo observados casos de falência primária neste estudo, não se pode afirmar que resultados semelhantes seriam encontrados utilizando-se amostra maior, já uma vez que a incidência de falência primária é, geralmente, menor que $5 \%{ }^{(6)}$. Como existem meios de preservação diferentes, com tempos de conservação variados, a escolha do meio deve ser com base, principalmente, no tempo de espera entre a preparação das córneas e a realização do transplante. Considerandose que quase $30 \%$ das córneas utilizadas para transplante, após a criação do CTU, permaneceram no meio de preservação por mais de 7 dias, recomenda-se o uso de meios com limite de conservação prolongado, maior que 7 dias.

Como o período avaliado foi o dos primeiros meses após a introdução do CTU, nova avaliação complementar seria ne- cessária, com o objetivo de mostrar se a alteração verificada no presente estudo se mantém ao longo do tempo.

C O N C L U S ÃO

Com base nos resultados deste estudo, conclui-se que a nova disposição do Sistema Estadual de Transplantes aumentou de forma estatisticamente significativa o período de permanência das córneas doadoras no meio de preservação, o que pode comprometer o tempo de vida útil do transplante e aumentar a incidência de falência primária, mesmo não sendo observados casos neste estudo.

A B S T R A C T

Purposes: 1) To verify the impact of the creation of the Single Technical Record (STR) at the University of Campinas (Unicamp) Hospital das Clínicas, on the preservation period of corneas which were used in elective penetrating keratoplasties, and 2) to compare the primary failure incidence in cornea penetrating keratoplasties regarding the periods before and after the creation of STR. Methods: A retrospective study was conducted at the Unicamp Hospital, which evaluated 15 consecutive cornea penetrating keratoplasties between January $1^{\text {st }}$ and April 30 ${ }^{\text {th }}, 2000$ and 24 consecutive penetrating keratoplasties between May $1^{\text {st }}$ and September $20^{\text {th }}$ of the same year (corneas under the control of the STR), totaling 39 keratoplasties. Results: The mean time between cornea preparation and transplantation was 3.8 days $( \pm 1.78)$ in the period before STR creation, and 6.0 days $( \pm 2.97)$ after STR creation, representing a $36.7 \%$ increase in the preservation time. There was a statistically significant difference $(\mathrm{p}=0.02)$ between the two groups. No corneal primary failure was observed among the 39 transplanted patients in both groups. Conclusion: Based on the results of this study, it can be concluded that this new concept of the State Transplantation System has caused a statistically significant increase in the conservation period of corneas, which may reduce the period of a clear transplant due to an increased loss of endothelial cells, as well as increase the primary failure incidence or result in a high number of corneas that cannot be used due to having exceeded the preservation time recommended by the literature.

Keywords: Tissue preservation; Corneal transplantation; Tissue banks/organization \& administration; Hospital information systems; Tissue donors

REFEREN C I A

\footnotetext{
1. Estado de São Paulo. Secretaria de Estado da Saúde. Resolução no SS12 de 20-01-2000. Dispõe sobre a estrutura organizacional e operacional do Módulo de Transplante de Córneas. Diário Oficial. São Paulo [citado em 2002 jan 15]. Disponível em URL: http://www.saude.sp.gov.br/html/fr_legi.htm

2. McCarey BE, Kaufman HE. Improved corneal storage. Invest Ophthalmol 1974;13:165-73.

3. Wong SK, Gottsch JD, Green R, Chen $\mathrm{CH}$, Stark WJ. Corneal graft survival
} 
in the cat with prolonged preservation in McCarey-Kaufman and K-Sol media. Arch Ophthalmol 1988;106:981-5.

4. Bourne WM. Endothelial cell survival on transplanted human corneas preserved at $4^{\circ} \mathrm{C}$ in $2.5 \%$ chondroitin sulfate for one to 13 days. Am J Ophthalmol $1986 ; 102: 382-6$
5. Molina L, Souza RB. Estudo experimental do meio de McCarey-Kaufman Rev Bras Oftalmol 1992;51:43-9.

6. Wilhelmus KR, Stulting RD, Sugar J, Khan MM. Primary corneal graft failure [commented on Arch Opthalmol 1995;113:1554-5]. Arch Ophthalmol 1995; 113:1497-1502.

\section{Il Congresso da}

\section{Sociedade Brasileira de \\ Administração em Oftalmologia}

\section{E 5 DE JULHO DE 2.003 \\ Blue Tree Convention Plaza \\ SÃO PAULO - SP}

PRO M O ÇÃ O : SBAO

IN FO RMAÇÕES: JDE Comunicação e Eventos

Tels.: (11) 289-4301/ 287-9378

Fax: (11) 288-8157

E-mail: jdecomev@uol.com.br 